\title{
NIETZSCHE Y LA FILOLOGÍA CLÁSICA: UNA RENOVACIÓN DIONISÍACA
}

Nietzsche and classical philology: a Dyonisian renewal

\author{
David Hernández de la Fuente
}

Universidad Complutense de Madrid

\begin{abstract}
Resumen: Esta contribución versa sobre la preocupación de Nietzsche por el concepto y método de la filología clásica y la renovación que propone a lo largo de su trayectoria académica como filólogo y filósofo. Tras unas consideraciones generales sobre el origen del concepto y método de filología y su reinvención en las «ciencias de la Antigüedad» a partir de F. A. Wolf, se analiza la manera en que Nietzsche abordó la crisis de la filología clásica en su época. Su uso de las religiones mistéricas y, en concreto, de Dioniso como símbolo de una Antigüedad viva y vital ejemplifica la idea que Nietzsche tenía de la labor del filólogo clásico, cuya labor en vez de centrarse en explicar el pasado debía constituirse como una crítica cultural del presente. Se evalúa también el impacto que deberían tener, en el contexto actual de crisis de las humanidades y pérdida de peso de las lenguas clásicas en el currículum de secundaria y de la universidad, las obras del Nietzsche filólogo, que pueden ser fácilmente accesibles, en nueva traducción castellana, con notas y comentarios, en el tomo II de sus Obras Completas publicado en 2013.

Palabras clave: concepto de filología clásica - Nietzsche - obras filológicas de Nietzsche - Dioniso
\end{abstract}

ABSTRACT: This contribution is about Nietzsche's concern for the concept and method of Classical Philology and the renewal that he proposed throughout his academic career as a philologist and philosopher. After some general considerations about the origin of the concept and method of philology and its reinvention in the «sciences of antiquity» from F. A. Wolf onwards, we analyze the way in which Nietzsche addressed the crisis of Classical Philology in his time. His use of the mystery religions and, in particular, of Dionysus as a symbol of a living and vital antiquity exemplifies Nietzsche's idea of the work of the classical philologist, whose role instead of focusing on explaining the past should be a kind of cultural critic of the present. This paper also assesses the impact that Nietzsche's philological work should have nowadays, in the current context of the crisis of the humanities and the classical languages in the curriculum of secondary and higher education. The philological works of Nietzsche are now easily accessible in a new Spanish translation, with notes and comments, in Volume II of his Complete Works, published in 2013.

Keywords: concept of Classical Philology - Nietzsche - Nietzsche's Philological Works - Dionysus

Si hay que creer a Friedrich Nietzsche, la filología clásica, al menos tal y como la entendemos hoy, tiene acta de nacimiento hace doscientos cuarenta años: más concretamente el 8 de abril de 1777, fecha en la que Friedrich August Wolf 
(1759-1824) se matriculó en la Universidad de Gotinga como studiosus philologiae. Una década más tarde Wolf publicaría sus Prolegomena ad Homerum, sentando las bases del método histórico-crítico que, como un salto de gigante frente a la antigua e idealizada visión de la Antigüedad grecolatina, pretendía estudiarla por vez primera con pretensiones científicas. Así surgía una «ciencia de la Antigüedad» (Alterthums-Wissenschaft) que el propio Wolf definía como la «disciplina que abarca el conjunto de conocimientos que, con los hechos, la ordenación política y la literatura de los pueblos antiguos, nos informa sobre su cultura, sobre la lengua, las artes, las ciencias, las costumbres, la religión, las características nacionales». Se utilizaba como sinónimo para esta ciencia una vieja y desusada

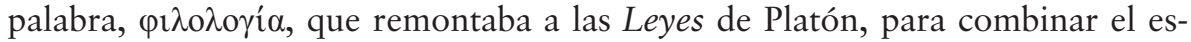
tudio documental del mundo antiguo y el panorama histórico con la pretensión de obtener una «idea de la Antigüedad concebida como un todo», con el ímpetu racionalizador y sistematizador del conocimiento científico del pasado que iba a culminar en el positivismo de finales del siglo xix. No por casualidad, en el currículo universitario alemán, que se formara en embrión cuando Wilhelm von Humboldt establece las bases de la Universidad de Berlín en 1810, estas «ciencias de la Antigüedad» habrían de tener un lugar de excepción en la formación del estudiante, como señala el énfasis el estudio de la filología clásica.

Huelga recordar que los orígenes de esta disciplina se encuentran en el comentario y exégesis de textos poéticos de aliento mítico o sagrado, desde los diálogos platónicos, a la tradición alejandrina, en sus famosos Biblioteca y Museo. Aunque hay que mencionar también que en principio $\varphi \imath \lambda \lambda^{2} o_{0} \alpha^{1}{ }^{1}$ no se refería a tales menesteres, sino que más bien se relacionaba con el «gusto por el discurso», pues los antiguos griegos se refirieron tradicionalmente a lo que hoy entendemos por filología con la expresión $\gamma \rho \alpha \mu \mu \alpha \tau$ lo que concernía a la creación literaria. La littera latina frente a la litteratura se

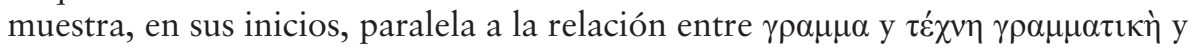
en el mundo romano Quintiliano testimonia esta equivalencia con nuestra filología actual: grammatice, quam in Latinum transferentes litteraturam vocaverunt ${ }^{2}$. Sin embargo, este sentido oscilará desde muy pronto hacia la obra y la erudición literaria, por un lado, pues la palabra litteratura, ya en latín, aparece atestiguada, en general, para refirirse al escritoliterario ${ }^{3}$ mientras que, por otro, se alude así a la cultura libresca o erudición «filológica»"

Se pueden sondear, pues, desde los propios orígenes de la filologíados almas que dentro de ella han de convivir, no siempre de forma pacífica, abarcando la erudición noticiosa de la hermenéutica pegada al texto, historicista, puntillosa y anticuaria y, a la vez, la visión general de la cultura letrada con su necesario vuelo interpretativo y panorámico, proyectado por fuerza sobre el presente. Ambas tendencias no dejarán de atormentar a los filólogos hasta nuestros días, como bien se evidenció desde el propio nacimiento - y varios renacimientos- de la disciplina. Si en el Renacimiento el latín litteratura se usa como sinónimo de «cultura

1. Cf., p. e., Н. Kuch, ФІ in der Tradition bis zur ersten überlieferten lexikalischen Festlegung, Berlín: Akademie, 1965.

2. Quintiliano 2, 1, 4; cf. Íd. 2, 14, 3.

3. Cicerón, Part. 7, 26.

4. Tertuliano, Spect. 18 
letrada», pasando a designar el conocimiento escrito puramente humanístico (litterae humaniores), las diversas lenguas nacionales heredan este sentido experimentando un cambio semántico en el Siglo de las Luces que orienta el concepto hacia los estudios literarios, cuando la «literatura» pasa a designar el grupo de obras de arte literario compuestas en una determinada lengua, país o período (francés littérature, 1764, alemán, Literatur, 1758).

Las letras serán así objeto de estudio, sincrónico o diacrónico, propiciando el nacimiento de la pretensión de estudiar científicamente el fenómeno literario como definitorio de un pueblo, en los albores del romanticismo, y con la gran ciencia filológica de F. A. Wolf y sus sucesores. El propio Wolf oscila, en sus consideraciones en dos obras clave, los Prolegomena ad Homerum y la Darstellung der Alterthums-Wissenschaft, entre esas dos tendencias mencionadas pues postula, por un lado, el método científico o histórico-crítico como una suerte de iter investigador implacable y objetivo, desvinculado de la realidad histórica y contemporánea, pero, por otro, propone la función inspiradora y cultural de la filología clásica como un puntal para la sociedad contemporánea.

En cuanto al método, la filología clásica se centra desde su origen en un objeto es tan simple como el siguiente: leer, comprender y explicar los textos. O, recordando las taxonomía del profesor Lasso de la Vega, en una operación que consiste en: 1) probar la validez y hallar la significación de los testimonios antiguos; 2) encontrar la íntima conexión entre los diversos y múltiples aspectos del mundo clásico; 3) describir en lo posible ese mundo unitario de la cultura antigua; 4) buscar la línea de continuidad entre la Antigüedad clásica y el mundo moderno ${ }^{5}$. El Medievo latino y bizantino heredó esa formula magistral de la gramática antigua, especialmente en lo que se refiere a los textos sagrados, a su fijación, conservación y comentario ${ }^{6}$, con una metodología que preludiaba el tópico humanista del festina lente con la férrea disciplina de los copistas tardoantiguos y medievales, de felix intentio y laudanda sedulitas ${ }^{7}$. Clásica es la filología por excelencia, tanto renacentista como ilustrada, que hará volver la mirada hacia los textos de la Antigüedad grecolatina desde la época de los humanistas a la de los gramáticos alemanes.

Como bien vio Nietzsche la filología es una disciplina a medio camino entre el arte y la ciencia, un saber que podríamos definir como profundamente humano - por lo rico, imperfecto y contradictorio, cargado de connotaciones y hallazgos afortunados, prejuicios y mixtificaciones que puede resultar-, pero en todo caso apasionante en su concepto, desarrollo y aportaciones. Filología es, citando a Antonio Tovar, «una habilidad, un arte: consiste simplemente en tomar un texto y poderlo explicar bien, sin dejar ningún punto oscuro. Lo que ha sucedido siempre en cada caso es que la filología, por una parte, consigue mucho más de lo que se

5. J. S. Lasso de la Vega, «El profesor de lenguas clásicas y el Humanismo», en Íd. (ed.), La enseñanza de las lenguas clásicas, Madrid: Rialp, 1992, pp. 18 ss.

6. P. e., R. Pfeiffer, Historia de la Filología Clásica, 2 vols., Madrid: Gredos, 1981 [orig. Geschichte der klassischen Philologie, Múnich: Beck, $\left.{ }^{2} 1978\right]$ y una larga tradición de trabajos desde el de U. v. Wilamowitz, Geschichte der Philologie, en A. Gercke y E. Norden (eds.), Einleitung in die Altertumswissenschaft, vol. 1, n. ${ }^{\circ}$ 1, Leipzig/Berlín, 1921, o W. Kroll, Historia de la Filología Clásica, Barcelona: Labor, 1953.

7. Casiodoro, Inst. I 301. 
había propuesto; por otra, se queda demasiado corta. De un lado, lo que había sido, en la idea previa, un delicado y sencillo instrumento gramatical, un arte práctica, se convierte en una serie de conocimientos muy complicados; más aún: en un conocimiento ordenado y sistemático, en una ciencia, casi en una enciclopedia. Entran en ella, ya no solo la gramática, sino la historia, la arqueología, la mitología, la geografía. Y entra, además, no ya solo la explicación de un texto dado, sino la preparación de un texto legible, libre de erratas y de corrupciones, la fijación de un texto lo más próximo posible a lo que pudo escribir el autor, o a lo que se imagina que es autor» ${ }^{8}$.

En estas líneas Tovar apunta toda la grandeza y las carencias de la filología, si se nos permite usar esta expresión, toda su problemática ${ }^{9}$, entre arte y ciencia, y su alcance, más allá de lo imaginable, como verdadera enciclopedia de saberes. Y esto es más cierto, si cabe, en el caso de la filología clásica, en cuanto trata lenguas, autores y obras alejados en el tiempo, aureolados de un prestigio sacro para nuestra cultura, en una época lejana en que se difuminan los conceptos de obra, autoría, originalidad, transmisión y texto. La filología, según el enfoque de aquella «ciencia de la Antigüedad"que inicia Wolf, no podía, en efecto, entenderse como un fenómeno aislado del contexto histórico y social en la que nace y se desarrolla, tanto del pasado como de lo contemporáneo. Su objeto, igualmente, se debía transformar con el devenir de las edades, de las corrientes espirituales y de pensamiento, y no conformaba un todo fijo, a la luz de la época que recibía el legado clásico. Pues es bien sabido que cualquiera de las transformaciones culturales de occidente se han debido - $\mathrm{O}$ al menos han estado condicionadas de alguna manera- por una relectura de los textos que se consideran clásicos, los grecolatinos.

Pero en algún momento del devenir de esa ciencia recién constituida como disciplina autónoma, una de las almas quiso prevalecer sobre la otra y lo hizo abusando de una excesiva rigidez. Contra ella, y con espíritu abierto e integrador, se rebeló en cierto momento un filólogo clásico que volvió, por un lado, a las bases de lo que había sido la filología antigua - defendiendo que un filólogo ha de ser lector pausado y divulgador de lo que lee- y, por otro, renovando de forma inspirada $-\mathrm{y}$ ciertamente dionisíaca - esta ciencia, que le sirvió como base para un discurso filosófico amplio y de alto vuelo. Tal fue el pensador y filólogo Friedrich Nietzsche que desde la década de 1860 empezó a interesarse por el concepto y método de la filología para conjurar los grandes riesgos que el abuso de una de las dos almas, la de una filología excesivamente tecnicista y rígida, conllevaba en su época, y acaso también en la nuestra: una cierta cerrazón gremial e hiperespecialización baldía.

Hay que recordar que el objeto de la filología no es otro que la capacidad más nítidamente humana; el lenguaje, la comunicación, y, más allá, el uso del lenguaje para crear belleza. Tal es lo que aún recoge hoy nuestro diccionario de la Real Academia como "poesía». Y, hablando del valor universal de la poesía griega, Friedrich Schlegel entendía en ese sentido profundamente humanista la filología, que es capaz de fundamentar la belleza del todo en el estudio de algo

8. A. Tovar, Lingüística y filología, Madrid: Revista de Occidente, 1944.

9. Entendida en el sentido de Althusser (Pour Marx, Paris: Maspero, 1965), como el conjunto ordenado de conceptos y objetos que configuran una ciencia. Una ciencia «nace» cuando un científico elabora «el concepto de su objeto». 
parcial pero precioso como unos versos de la lírica griega ${ }^{10}$. Así, Nietzsche describe en el prólogo de Aurora (1881) la filología como una disciplina «que exige ante todo una cosa de quienes la admiran y respetan, situarse al margen, tomarse tiempo, aprender la calma y la lentitud -, al ser el arte y el saber del orfebre de la palabra, que ha de realizar un trabajo delicado y cuidadoso y nada logra si no es con tiempo de lento. Justo por eso es hoy más necesaria que nunca, justo por eso es lo que más nos atrae y nos fascina, en una era que es la del 'trabajo', quiero decir: la de la precipitación, la de la prisa indecente y sudorosa que pretende 'acabar' todo de inmediato, incluso un libro, sea nuevo o viejo: - la filología no acaba nada con tanta ligereza, sino que enseña a leer bien, es decir, lenta, profunda, respetuosa, cuidadosamente, con cierta malicia y las puertas siempre abiertas, con sensibilidad en la mirada y en el tacto» (A, prólogo, 5).

Pero en época de Nietzsche, el propio concepto de la filología clásica ya no era unívoco y había entrado en crisis. Fue la cerrazón y la miopía de parte de sus colegas lo que paulatinamente le hizo despegarse del consenso filológico hasta dar a luz el magnífico libro El nacimiento de la tragedia, considerado un escándalo entre los filólogos más estrictos y tradicionalistas, como Wilamowitz, Diels o incluso Usener. La frase condenatoria de Reinhart de que «la historia de la filología no reserva ningún lugar para Nietzsche» aún resuena en los oídos de muchos habiéndose convertido en tópico. La opinión común quiere que muy pronto se le hubieran abierto las puertas de la academia alemana a aquel joven filólogo y que, tras una caída del caballo —su interés por san Pablo no es baladí-, que se sitúa entre la década de 1860 y 1870 y que tiene en su cátedra de Basilea el epicentro, Nietzsche habría experimentado una conversión a la filosofía, un cambio de rumbo total. Desde entonces el denuesto a Nietzsche, encarnado en La filología del futuro de Wilamowitz, habría sido unánime y la obra del Nietzsche filólogo reducida a la categoría de anecdótica. Pero no hay que desdeñar en absoluto ni su obra anterior a ese deslumbramiento ni su propia autoconciencia posterior de filólogo.

La aparición en 2013 del volumen II de las Obras Completas de Nietzsche en la editorial Tecnos, que contiene sus «Escritos filológicos», bajo la dirección de Diego Sánchez Meca, nos recordó que estos tópicos han de ser repensados y revisitados, como se apunta ya en su introducción general, aludiendo al «proceso de revalorización del Nietzsche filólogo» ${ }^{11}$. A tres años de la aparición de esa nueva traducción y edición conjunta de las obras del Nietzsche filólogo podemos apuntar aquí algunas claves del impacto que ha tenido y, sobre todo, del que debe tener. La reivindicación del Nietzsche filólogo no es, ciertamente, algo nuevo. No hubo que esperar a la aparición a comienzos del siglo xxI del fundamental trabajo de James I. Porter ${ }^{12}$, donde se proponía una inteligente síntesis entre el Nietzsche filólogo y el filósofo y se rehabilitaba enteramente su visión precursora de una filología renovada, sino que, ya desde antiguo, lo rescató de esa damnatio memoriae de los puristas eruditos una nómina de filólogos ilustres: unos más alejados de nosotros, como en los casos de Bursian (1898) o Cornford (1912), y otros que con

10. F. Schlegel, Sobre el estudio de la poesía griega, ed. de B. Raposo, Madrid: Akal, 2001.

11. D. Sánchez Meca (ed.), F. Nietzsche, Obras Completas, vol. II, Madrid: Tecnos, 2013, p. 17.

12. J. I. Porter, Nietzsche and the Philology of the Future, Stanford, Stanford UP, 2000. 
justicia pueden ser considerados padres fundadores de la filología actual, como Adrados (1970) o Gigante (1974). La lectura renovada de los escritos nietzscheanos sobre filología clásica, editados, traducidos, introducidos y anotados en castellano ahora con auténtica acribia por un solvente equipo de expertos, demuestra a nuestro ver la vitalidad actual de las ideas que tenía el filósofo sobre la filología clásica.

Nietzsche parte de una fascinación ambivalente por la obra y figura de Friedrich August Wolf como fundador de aquella filología científica y reflejo también de las dos almas mencionadas. El filósofo siempre estuvo interesado por la problemática del método histórico-crítico defendido por la filología clásica desde la época de Wolf, pero mantuvo también discrepancias a partir de un cierto periodo en el que la estrechez de miras de aquella filología que pretendía ser objetiva y meramente positivista, y basarse en la descripción detallada y en la investigación metódica de los fenómenos literarios sin tener en cuenta otras variables ${ }^{13}$.

No es extraño que al intentar alzar un vuelo filosófico el joven profesor de Basilea chocara con las interpretaciones de la filología más tradicional. Pero no hay que olvidar que la vinculación de Nietzsche con la filología más estricta desde su etapa de formación y el método histórico-crítico comienza en la escuela Pforta, cuando tendrá el influjo del profesor Friedrich Ritschl, cuya es la divisa que dice que «es mejor errar metódicamente que encontrar la verdad sin método, es decir, por casualidad» (besser methodisch irren als unmethodisch, d. h., zufällig das Wabre finden). Pero pronto empieza Nietzsche a intentar redefinir el método postulando el escepticismo como freno para que los filólogos no transmitan los prejuicios del pasado. Así se ve en su trabajo sobre Demócrito: su intento de aplicar el concepto de duda sobre aspectos básicos de la tradición de la filología, como el de autoría u originalidad, como estudia Porter, representa una etapa previa a la conjunción de filología, pensamiento e inspiración que habrá de llegar con el recurso a la poética dionisíaca.

Precisamente hoy, tras el giro que ha tomado la filología clásica en el último cuarto del siglo xx y en la actualidad, tan claramente puesto en tela de juicio por el estupendo ensayo de V. D. Hanson y J. Heath Who Killed Homer? The Demise of Classical Education and the Recovery of Greek Wisdom (New York: The Free Press, 1998), el camino de duda y de iluminación que recorrió Nietzsche parece especialmente sugerente. Sus lecciones y reflexiones filológicas siguen siendo válidas a día de hoy y están muy de actualidad. Hanson y Heath criticaron en su día la cortedad de miras de los clasicistas como una de las razones para el declinar de los estudios de filología clásica en las facultades de todo el mundo, por causa de la hiperespecialización, la primacía de parámetros de productividad investigadoras absurdos e importados de las ciencias experimentales, la insistencia en la literatura secundaria y en las tendencias de investigación à la mode y la desidia a la hora de enseñar en las aulas en la gran tradición filológica pegada al texto. Como apunta Carlos García Gual, «[l]a tesis de fondo puede parecer tal vez un tanto excesiva: pienso que a Homero no lo mataron los helenistas universitarios,

13. E. Nasser, «Nietzsche et la réforme méthodologique de la philologie: le problème de la scientificité dans le contexte des études classiques», en C. Denat y P. Wotling (eds.), Nietzsche: les premiers textes sur les Grecs, Reims: Épure, 2016, pp. 51-78. 
aunque quizá muchos colaboraran a su entierro. Del declive de los estudios clásicos Hanson y Heath acusan a los académicos de haber dejado de ocuparse de los grandes autores y los textos fundamentales del legado clásico para especializarse en temas menores, más rentables para la trepa universitaria, atentos a la jerga posmoderna y lo políticamente más correcto, rebajando su profesión humanista a un mundo pequeño, mediocre, de citas mutuas, bizantinismo y pedantería algo mafiosa» ${ }^{14}$.

Frente a esto, la crítica de Nietzsche a la filología clásica, desde los años de Basilea, cobra hoy de nuevo todo su vigor cuando atestiguamos la decadencia definitiva del griego y el latín en la secundaria, relegados a un papel de comparsas en los itinerarios de humanidades, y la pérdida de peso de las clásicas en la universidad. Es irónica, pues, la situación de la filología clásica a cien años de aquel solemne acto de apertura de la Universidad de Berlín en 1900, en el que Wilamowitz - el gran enemigo de esa filología inspirada del profesor de Basilea - proclamara que la filología clásica era la ciencia más avanzada y la abanderada del futuro. Si ya entonces la filología clásica había entrado en la crisis que denunciara Nietzsche, que acusaba la falta de visión panorámica de ciertos estudiosos, hoy su censura sigue vigente. «No podemos negar de hecho — decía el filósofo en una carta de 6 de abril de 1867-que a la mayoría de los filólogos les falta esa visión global sublime de la Antigüedad, porque se ponen demasiado cerca del cuadro y examinan una pequeña mancha de aceite en vez de maravillarse de los rasgos grandes y audaces de todo el cuadro» (CO I, 450).

Hoy, por cierto, esa tendencia a la hiperespecialización que acusaban a finales del siglo xx Hanson y Heathse ha pronunciado aún más, ya que los filólogos tienden a ese conocimiento «de manchas de aceite». Al fracaso de la filología en el marco de los estudios humanísticos dedica Nietzsche en 1876 conferencias y reflexiones que muestran el olvido del ideal estético que la Antigüedad había supuesto para el clasicismo de Weimar al confluir en un resultado paradójico: el riguroso método de los filólogos, en vez de conducir a la armonía, había llevado a una especie de nueva barbarie sin sentido ${ }^{15}$. Así, el fracaso de la filología había sido doble, como señala Diego Sánchez Meca $(2016,46)$, «primero como programa de educación por la contradicción inevitable entre los ideales del espíritu griego y los de la cultura moderna. Y segundo, también habría fracasado como ciencia a causa de su degeneración positivista que la reduce a un conjunto de meras tareas técnicas y mecánicas (investigación de las fuentes, edición y comentario de textos, etc.), simple conocimiento histórico de detalles sin más finalidad que la acumulación y el engrandecimiento del mismo».

Esta crítica nietzscheana suena exactamente a lo que sucede en la actualidad, cuando ese «conocimiento de detalles» es precisamente lo que premian las agencias e instituciones de investigación, copiando modelos ajenos que les quedan ridículos al fijarse en cosas como número de citas, impacto y otros llamados indicios de calidad que no suelen demostrar una calidad ni una utilidad ni mucho menos

14. C. García Gual, «El debate de las humanidades»: Claves de razón práctica 243 (2015), 136155.

15. D. Sánchez Meca, «La novedad metodológica de los cursos de Nietzsche sobre Historia de la Literatura Griega (1874-1876)», en C. Denat y P. Wotling (eds.), Nietzsche: Les premiers textes sur les Grecs, Reims: Épure, 2016, pp. 45-47. 
la inteligencia de los trabajos evaluados. Ni que decir tiene que la decadencia de los estudios clásicos, en términos de número de estudiantes tiene hondas raíces: quizá sería exagerado remontar la crisis a la deriva de la ciencia de la Antigüedad desde la época de A. Boeckh (1785-1867) o F. Schleiermacher (1768-1834), cuando se empiezan a decantar dos ámbitos en el devenir del método históricocrítico, hacia la historia y hacia la estricta hermenéutica textual. Pero en esas andamos también hoy, si hemos de atender a la filología clásica en su estado actual y perspectivas, ante la apabullante pérdida del papel dominante que tenía esta disciplina en el currículo académico y cultural de Occidente durante los dos últimos siglos y que se ha producido, especialmente, en los últimos cincuenta años. Es un lugar común entre los profesores de clásicas en secundaria lamentarse por cada nueva reforma educativa, que merma las horas de latín y griego. Puede que su mismo gremio, y no solo el signo de los tiempos, haya sido históricamente corresponsable de esa decadencia.

Así, no sorprende que, ante el panorama de desazón y nostalgia que un grupo importante de filólogos clásicos siente en este devenir de la filología, se haya vuelto a las propuestas intuitivas y visionarias de Nietzsche para la mejora de esta disciplina y su imbricación social, a su sano escepticismo y al vitalismo que destilan las páginas de sus ensayos filológicos. Pero es que incluso son las metodologías más actuales de trabajo sobre el mundo antiguo, desde la historia de las mentalidades a los estudios de género, las que vuelven a leer sus textos de juventud y sus trabajos filológicos sobre el mundo griego, su literatura, sociedad y pensamiento, y reivindican en cierto modo su legado filosófico y también filológico como dos pilares ciertamente inseparables. Lejos quedan las condenas del rígido academicismo germano, representado por los ataques de todo aquel establishment académico que reaccionó de forma casi ofendida a la publicación de El nacimiento de la tragedia en 1872: era un gremio que había tenido enorme importancia y repercusión desde la fundación del sistema universitario prusiano en 1810 y cuya valía estaba sin duda sobredimensionada. La sociedad alemana, que había puesto la filología clásica en el centro de la educación y formación (Bildung) del individuo, podía reclamarle justamente, pensaba Nietzsche, unos frutos en la mejor de la propia sociedad, aunque lo único que había producido era más trabajo de investigación con un exceso infructuoso de especialización.

Sin embargo, en nuestro tiempo, y después de este panorama de decadencia de los estudios clásicos en nuestras escuelas y universidades, el estupendo primer libro filosófico-filológico de Nietzsche puede ser leído con gran vigencia. Otro tanto ocurre con sus contribuciones más puramente filológicas, recopiladas ahora y puestas al día en el estupendo volumen segundo de sus obras completas. La necesidad de superar también hoy el rigor hiperespecializado y la miopía científica de la que han hecho gala muchos de nuestros filólogos del siglo xx es precisamente lo que pone a Nietzsche más de actualidad que nunca. Se diría que ha de luchar su obra en ese sentido una segunda batalla, a través de la relectura atenta en nuestras facultades de filología de sus escritos inéditos acerca de la filología clásica y de El nacimiento de la tragedia, como resultado de esta conjunción del renovado método filológico nietzscheano.

Parte de la renovación que emprende Nietzsche de la visión de la Antigüedad se basa en revindicar el arcaísmo griego —otro comienzo para la filologíafrente a un clasicismo que empieza a no estar en su punto de mira: así se ve en la 
preferencia por los presocráticos frente a Platón y en la reflexión que realiza sobre algunos fenómenos griegos considerados marginales en la tradición de las ciencias de la Antigüedad alemanas pero que, a partir de su obra, empiezan a cobrar un relieve inusitado. Un tema clave en esta reformulación es el de la búsqueda de los extremos: arcaísmo y edad tardía, lírica y pensamiento arcaicos y tardo antigüedad y época bizantina, los preplatónicos y Suidas. Otro es el de la necesaria formación filosófica de los filólogos, que se explicita en Enciclopedia de la filología clásica, cuyo epígrafe 2 comienza con humor: «Se ha propuesto en muchas ocasiones que cada futuro especialista estudie primero la filosofía durante un año a fin de que no acabe por parecerse a un obrero de la fábrica que hace tornillos año tras año. Es preciso que el filólogo clásico se apoye constante y firmemente en la filosofía con el fin de que su reivindicación del clasicismo de la Antigüedad, frente al mundo moderno, no suene a pretensión ridícula. Pues, de este modo, emite un juicio».

En esalínea Nietzsche se aplicó, en sus textos dedicados al concepto de filología clásica notablemente su Antrittsvorlesung en Basilea Homero y la filología clásica y también su citado curso Enciclopedia de la filología clásica, a intentar restituir el mundo antiguo en su unidad viviente, es decir, en lo que hoy nos tiene que decir hoy a todos nosotros. Por eso no es de extrañar que, para explicitar este ansiado retorno de una Antigüedad viva y sentiente, Nietzsche usara un símbolo poderoso como es Dioniso, que surgirá naturalmente de sus estudios filológicos y de su concepción filosófica a partir de su interés por la religión griega y por su vertiente de los misterios. El interés por las religiones mistéricas es clave en el comienzo del desapego nietzscheano de la Altertumswissenschaft tradicional y en su propuesta de renovación de la filología clásica ${ }^{16}$ : los misterios perfilan para Nietzsche una de las esencias fundamentales del helenismo. No llegó el filósofo alemán a conocer el gran desarrollo de los estudios sobre la religión griega en el ámbito de los misterios griegos que tendría lugar a comienzos del siglo xx, notablemente a partir de la obra emblemática de Erwin Rohde, Psyche, sobre el concepto del alma en la antigua Grecia, o de los estudios señeros de Jane Harrison y de toda la escuela de los ritualistas de Cambridge en adelante, basados sobre las investigaciones antropológicas de Van Gennep. Ni pudo saber de los trabajos claves sobre el Dioniso de los misterios que marcaron la filología clásica a partir de entonces: pero es claro que su visión del dionisismo influyó sobremanera en esta rehabilitación del dios de los misterios, el más humano de los Olímpicos y a la vez el más extraño.

Nietzsche, como en tantas otras cosas, fue un pionero en constatar el profundo helenismo de los misterios y de Dioniso, adelantándose en un siglo a debates posteriores de la filología clásica y la historia de las religiones. Quizá por influencia del protestantismo algunos estudiosos de su época habían creído ver en los misterios una religiosidad más elevada que la religión políade. En El nacimiento de la tragedia se ve en los misterios la evocación de la unidad originaria, tanto en Eleusis como en los ritos dionisíacos, a modo de una raíz auténtica de la más pura religiosidad griega. Buscando la Antigüedad viviente, Nietzsche creyó ver en las religiones mistéricas una manera de resucitar toda la potencia vital de la Antigüedad.

16. Como apunta C. Santini, «La reflexión sobre las religiones mistéricas en la filosofía de Nietzsche»: Estudios Nietzsche 11 (2011), 83-98, a quien seguimos en este punto. 
El nacimiento de la tragedia deriva directamente de las clases en Basilea sobre lírica griega, en concreto desde su primer curso en el Sommersemester de 1869 y el del Sommersemester del año siguiente, sobre la tragedia de Sófocles ${ }^{17}$. La continuidad entre los primeros proyectos del Nietzsche filólogo, en su mayor parte esquemas de clases o apuntes inéditos - que se reúnen en el volumen II de sus Obras Completas en castellano- muestran una clara continuidad con su posterior y famoso primer libro, como ha demostrado también el estudio de Porter (2000). El interés de Nietzsche se centra en las festividades de Dioniso y el ditirambo -género dionisíaco por excelencia de la lírica arcaica- como raíz de la tragedia: «el estado extático en los festivales dionisíacos es el lugar de nacimiento de la música y del ditirambo ${ }^{18}$. En concreto, en cuanto al dionisismo, religiosidad, profunda y música, drama y sacrificio se combinan en el mito gracias a la perspectiva ética del más allá que proporcionaba su vertiente órfica. El mito de Dioniso Zagreo versa sobre la muerte y resurrección de un primer Dioniso niño despedazado por los titanes a instancias de Hera, y cuya sangre y carne son consumidas por ellos, salvo un pequeño órgano, normalmente el corazón, que serviría para generar al segundo Dioniso, el tebano. El tema heroico del dios sacrificado se le antoja a Nietzsche el núcleo originario de la tragedia ática, según El nacimiento de la tragedia (10), en la que cada héroe trágico reproduciría ese patrón del Dios que muere y resucita, del dying god como estudiaría Sir James Frazer. Es una interpretación que ha sido modernamente retomada, desde los estudios sobre el sacrificio en el mundo griego de René Girard o Walter Burkert, en 1972, hasta los trabajos de Richard Seaford. Los dioses de los misterios, primordiales deidades de la vegetación, derivarían para Nietzsche en el mundo griego en una tendencia mística que aparece en el cambio de mentalidad que se puede atestiguar, en cuando a la doctrina del alma, en el siglo vi a. C., coincidente con algunos llamados presocráticos: según Nietzsche estas ideas influyen sobremanera en el nacimiento de la filosofía griega, como en el caso de Anaximandro (La filosofía en la época trágica de los griegos 3.5).

A Nietzsche le fascinaba el contenido simbólico de los mitos que subyacen a la experiencia mistérica, especialmente el mencionado mito de Dioniso Zagreo. La más importante implicación en ese sentido es que los titanes, que habían ingerido al niño dios fueron fulminados por el rayo de Zeus enfurecido, según la interpretación neoplatónica, y que de las cenizas resultantes surgió la raza humana. De ahí surge la idea, en la Antigüedad, de que en el ser humano hay una parte titánica y malvada, pues procede de las cenizas de los malvados titanes, pero también una parte noble y divina, el alma, a resultas de haber ingerido aquellos al niño Dioniso, un dios, en un aspecto escatológico de los misterios — pecado original y filiación divina del ser humano- con el que Nietzsche se ocupa por su evidente analogía con los misterios del cristianismo. A ese respecto cabe señalar su fascinación por la figura de Pablo de Tarso, al que considera verdadero padre fundador de la religión cristiana gracias a su adaptación sincrética de los misterios griegos. Esta experiencia mistérica se perpetuará en cierto modo, aunque des-

17. B. von Reibnitz, Ein Kommentar zu Friedrich Nietzsche, Die Geburt der Tragödie aus dem Geiste der Musik, Stuttgart: Metzler, 1992, pp. 28-29.

18. Cita de Nietzsche en B. von Reibnitz, op. cit., p. 30. 
virtuada, a través del cristianismo paulino, que para Nietzsche trastoca el alma helénica. Todos los cultos vitales de la Grecia antigua, de los ciclos del pan y el vino, Eleusis y Dioniso, se integran según esta visión en el cristianismo, cuya historia de éxito, de ser un pequeño movimiento popular surgido en el seno del judaísmo a convertirse en una religión universal y una enciclopedia de cultos diversos que conquista realmente el mundo, puede deberse a esa función de catalizador de la religiosidad mediterránea, de los misterios griegos y orientales ${ }^{19}$.

La comparación que sobresale en el fondo es entre Dioniso y Cristo, con sus analogías pero también con sus diferencias. Esta pareja de dioses paralelos la toma Nietzsche de toda la tradición del idealismo alemán, intelectualizada, actualizada y superando las teorías en boga en la filología clásica alemana de su tiempo. Nietzsche, a partir de sus lecturas del Dioniso naturalista de Schelling ${ }^{20}$, y de la inspirada poesía cristológico-dionisíaca de Hölderlin ${ }^{21}$, tenía una conciencia clara de lo que significaba esta transferencia de redentores por el sacrificio y la sangrevino de ambos mundos para la historia de la cultura. Y ciertamente pretendía que simbolizasen un nuevo comienzo para la modernidad a través de su refundación no solo de la filología clásica y de los estudios sobre la Antigüedad, sino de la filosofía en general. En efecto, para su dionisología Nietzsche era muy sabedor de las controversias en torno al origen oriental del misticismo y de los cultos extáticos - y de Dioniso, que aún no había probado su raigambre griega, gracias al desciframiento de las tablillas micénicas a mediados del siglo xx-en las célebres y polémicas obras de G. F. Creuzer, Symbolik und Mythologie der alten Völker, besonders der Griechen (1819) y de C. A. Lobeck, Aglaophamussive, De theologiae mysticae Graecorum causis libri tres (1829), y también tenía en mente las tesis sobre el matriarcado de Bachofen. Era preciso superar las ideas imperantes que hacían proceder el misticismo griego de una raíz oriental y resituar el debate en lo que Dioniso (con su contraparte, Cristo, bien deslindada o neutralizada) podía decir de Occidente desde su propio interior. También le debe Nietzsche parte de su reinterpretación de Dioniso como metáfora de la potencia creativa para la humanidad del trasfondo místico y metafísico de la esencia del mundo a la idea de voluntad de Schopenhauer.

Pero el Dioniso de Nietzsche emprende un vuelo histórico-cultural propio como símbolo de una fuerza vital en el interior del ser humano que viene directamente de la antigua mentalidad religiosa de los misterios griegos y que, partiendo de una renovación de la filología clásica, también acabaría por proponer una refundación total de la vida humana. Dioniso como potencia arcaica y poderosa es la fuerza que lleva a la humanidad a una suerte de reversión hacia lo uno primordial, dotando de sentido metafísico interno al ser humano. Y hay una nueva

19. Cf. B. von Reibnitz, op. cit., p. 32; J. I. Porter, op. cit., p. 221 y C. Santini, op. cit., pp. 92-93, acerca de la lengua religiosa de Pablo y su relación con los misterios.

20. J.-M. Pailler, Les mots de Bacchus, Toulouse: Presses Universitaires du Mirail, 2009, pp. 91 ss. Para el Dioniso de Schelling, cf. en general J. E. Wilson, Schelling und Nietzsche. Zur Auslegung der frühen Werke Nietzsches, Berlín/Nueva York: W. de Gruyter, 1996.

21. M. Frank, El Dios venidero. Lecciones sobre la Nueva Mitología, Barcelona: Serbal, 1994 [Der kommende Gott. Vorlesungen über die Neue Mythologie, I parte, Fráncfort d. M.: Suhrkamp, 1982]; D. Mariño Sánchez, Historiografía de Dioniso. Introducción a la historiografía de la religión griega antigua, Santiago de Compostela, Universidad de Santiago, 2007, pp. 90-91. 
visión ariadnea del alma junto a Dioniso, a la que he dedicado recientemente un estudio $^{22}$, que aparece como un principio femenino o amor intelectualizado a lo divino que sufre en el hombre. El ditirambo será la forma expresiva, con toda su potencia poética y hermenéutica, de esta visión entre la Antigüedad y el futuro. Escribe Nietzsche en Ecce homo («Así habló Zaratustra», 8): «Jamás se ha compuesto algo similar, jamás se ha sentido, jamás se ha sufrido nada igual: así sufre un dios, un Dioniso. La respuesta a semejante ditirambo de la soledad del sol en medio de la luz sería Ariadna... iQuién sabe, excepto yo mismo, qué es Ariadna! De todos estos enigmas nadie hasta ahora tuvo la clave, dudo incluso de que alguien viera aquí alguna vez enigma alguno». Es especialmente en los Ditirambos de Dioniso (1888) donde Nietzsche, bajo la apariencia lírica, presenta una críptica reivindicación de este viejo dios cuyos mitos y ritos había querido contraponer a la Grecia usualmente estudiada por la filología clásica de su tiempo. Esos cantos «zoroástrico-dionisíacos», espléndidamente traducidos y comentados en el volumen IV de las Obras Completas de Nietzsche ${ }^{23}$, incluyen ciertamente un «Lamento de Ariadna» (Klage der Ariadne) que da fe de la importancia del ciclo de Dioniso y Ariadna en nociones clave del pensamiento de Nietzsche como el eterno retorno o el superhombre como resultado de esta teogamia mítica ${ }^{24}$.

Como la unión mística de Dioniso y Ariadna en el mito, así puede interpretarse también la renovación nietzscheana de la filología, una unión entre el filólogo y la obra, basada en la lectura pausada de los clásicos y la asimilación íntegra de su mensaje para transmitirlo en comunión con el alma antigua a los contemporános y a la posteridad. También hoy, en pleno siglo XXI, debe reivindicarse esta visión, incomprendida en su contexto positivista, que surge del espíritu de la música de Dioniso, de lo trágico heroico en la labor filológica, que requiere al menos tanta inspiración como erudición. Así refundaba secretamente Nietzsche la filología clásica como ciencia auténticamente global de la Antigüedad que unía pasado y presente con la amplitud de miras imprescindible y el carácter de crítica cultural.

En ese sentido, y combinando lo general con lo concreto, la visión panorámica y la especialización, Nietzsche recuerda a la filología de hoy que el filólogo

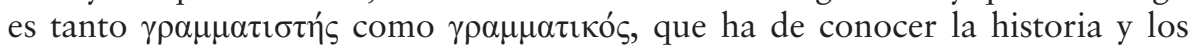
movimientos culturales y espirituales de cada momento estudiado, pero también implicarse en el pensamiendo contemporáneo y en sus debates, para encontrarse en condiciones de emprender su ardua labor de la hermenéutica superior de los textos antiguos que sea de provecho para el hombre de hoy. Por ello, creo que en las páginas del Nietzsche filólogo — que con tanto acierto se están releyendo y recuperando sin cesar en la actualidad - hay explícita una exigencia - o mejor dicho, una autoexigencia para los filólogos- de mantener una especial disposición de ánimo que evite en lo posible la falta de visión panorámica como defecto

22. D. Hernández de la Fuente, El despertar del alma. Dioniso y Ariadna. Mito y misterio, Barcelona: Ariel, 2017.

23. D. Sánchez Meca (ed.), F. Nietzsche, Obras Completas, vol. IV, Madrid: Tecnos, 2016.

24. Véase la influyente interpretación de Deleuze: p. e., G. Deleuze, Nietzsche et la Philosophie, Paris: PUF, 1962 y «Mystère d'Ariane»: Bulletin de la Société française d'études nietzschéennes (1963), 12-15. Para el enigma de Ariadna, cf. también W. Groddeck, Friedrich Nietzsche «DionysosDithyramben», vol. 2: Die «Dionysos-Dithyramben»: Bedeutung und Entstehung von Nietzsches letztem Werk, Berlín/Nueva York, W. de Gruyter, 1991, pp. 176 ss. 
de esa filología tradicionalmente estrecha de miras queparece oponer erudición a imaginación. La falta de esa imaginación, aparcada entre enormes bibliografías, aparatos críticos y índices de impacto, es una de las dolencias de la disciplina. Hay que apostar, como hizo Nietzsche con su renovación dionisíaca, por una filología clásica más intuitiva e imaginativa que tome el puso al pensamiento y a la sociedad. No por casualidad eligió Nietzsche el leitmotiv de Dioniso, como dios renovador y que se renueva a sí mismo a través de Ariadna, en apariencia extrañoy oriental, pero en ensencia interior y autóctono.

Como señala Sánchez Meca, «[l]o más significativo e importante del Nietzsche filólogo no es, en consecuencia, su práctica del método científico aplicado al establecimiento de los textos o de los hechos históricos de un modo acertadamente argumentado y objetivo, sino su investigación de los contrastes entre las condiciones culturales la Antigüedad y el presente, a partir de los cuales puede ser posible una crítica de la actualidad $»^{25}$. Y, en efecto, se diría que la reconceptualizacion que pretende Nietzsche de la filología clásica es una práctica de crítica cultural que se centra realmente en la mentalidad moderna y en sus prejuicios al comprenderse a sí misma a través de la Antigüedad. No se trata de conocer el pasado "como realmente fue» (wie es eigentlich gewesen), tal y como rezaba la divisa del positivista Leopold von Ranke, sino más bien de comprendernos mejor a nosotros mismos a partir de la Antigüedad. A eso hay que contraponer lo que Nietzsche afirmaba sobre la labor de la filología clásica y toda la ciencia histórica de la Antigüedad: «Si al filólogo le está encomendada la tarea de comprender mejor su propia época por medio de la Antigüedad entonces su tarea es eterna». Homero y la filología clásica o Enciclopedia de la filología clásica deben ser hoy textos básicos para todos los filólogos, pues en ellos se les avisa de que la Antigüedad no es revivida a través de esta disciplina sino que es la actualidad la que aparece con brillos renovados gracias a la luz que arroja sobre ella el mundo clásico: sin duda, la aportación clave del Nietzsche filólogo se centra en determinar en qué formas la filología — tanto como la propia filosofía — son síntomas de los hábitos culturales de la Modernidad, de su ideología e imaginario ${ }^{26}$. Esa labor de interpretación y crítica cultural para la filología clásica es uno de sus legados principales, como se desprende de la imprescindible lectura de sus obras filológicas.

25. D. Sánchez Meca (ed.), F. Nietzsche, Obras Completas, vol. II, Madrid: Tecnos, 2013, p. 19.

26. J. I. Porter, op. cit., pp. 4, 171, 273, 287. 